Int. J. Electrochem. Sci., 11 (2016) $10884-10894$

\title{
Electrochemical Impedance Spectroscopy Study for Cathodic Disbonding Test Technology on Three Layer Polyethylene Anticorrosive Coating under Full Immersion and Alternating Dry-Wet Environments
}

\author{
Yingchun Chen, Xinhua Wang ${ }^{*}$, Yingchao Li, Gang Zheng, Xiyuan Tu \\ College of Mechanical Engineering and Applied Electronics Technology, Beijing University of \\ Technology, Beijing, 100124, China \\ *E-mail: paper_bgdjd103@163.com
}

doi: $10.20964 / 2016.12 .83$

Received: 29 July 2016 / Accepted: 19 October 2016 / Published: 10 November 2016

\begin{abstract}
Cathodic disbonding of three layer polyethylene (3LPE) anticorrosive coating under alternating drywet and full immersion environments is now a serious problem associated with oil and gas pipelines. In this study, under such specific environment, electrochemical impedance spectroscopy (EIS) technology was used to study the process and mechanism of cathodic disbanding behavior of broken 3LPE anticorrosive coating in $3.5 \% \mathrm{NaCl}$ solution. The dry-wet cycle involved two steps of $12 \mathrm{~h}$ immersion followed by $12 \mathrm{~h}$ drying process. The results showed that broken 3LPE anticorrosive coating exhibited a starting potential of $-1.28 \mathrm{~V}$ (vs. SCE) $(-1.20 \mathrm{~V}$ (vs. CSE)) under full immersion environment. The impedance characteristic of broken 3LPE anticorrosive coating exposed to alternating dry-wet environment was similar to that under full immersion environment: the impedance of anticorrosive coating first increased and then decreased; however, the value of impedance under dry-wet process was significantly less than that under full immersion process. Dry-wet circulation significantly accelerated the corrosion reaction; moreover, anticorrosive coating failure rate was also significantly faster.
\end{abstract}

Keywords: Three layer polyethylene anticorrosive coating; Dry-wet alternate environment; Full immersion; Electrochemical impedance spectroscopy

\section{$\underline{\text { FULL TEXT }}$}

(C) 2016 The Authors. Published by ESG (www.electrochemsci.org). This article is an open access article distributed under the terms and conditions of the Creative Commons Attribution license (http://creativecommons.org/licenses/by/4.0/). 